\title{
Feeding India's Babies: Trends and Patterns in Infant and Young Child Feeding Practices Across India's States and Districts
}

\section{ABOUT THIS DATA NOTE}

Appropriate nutrition during early life, coming mainly from adequate infant and young child feeding (IYCF) practices, is essential for optimal growth and development. This Data Note describes the trends and patterns in key IYCF practices and food consumption patterns among children, summarizing state ${ }^{1}$ and district $^{2}$ data from the third and fourth rounds of National Family Health Surveys (2006 \& 2016).

\section{FIGURE 1 Trends in infant and young child feeding practices, between 2006 and 2016}

100

80

$\square 2006 \square 2016$

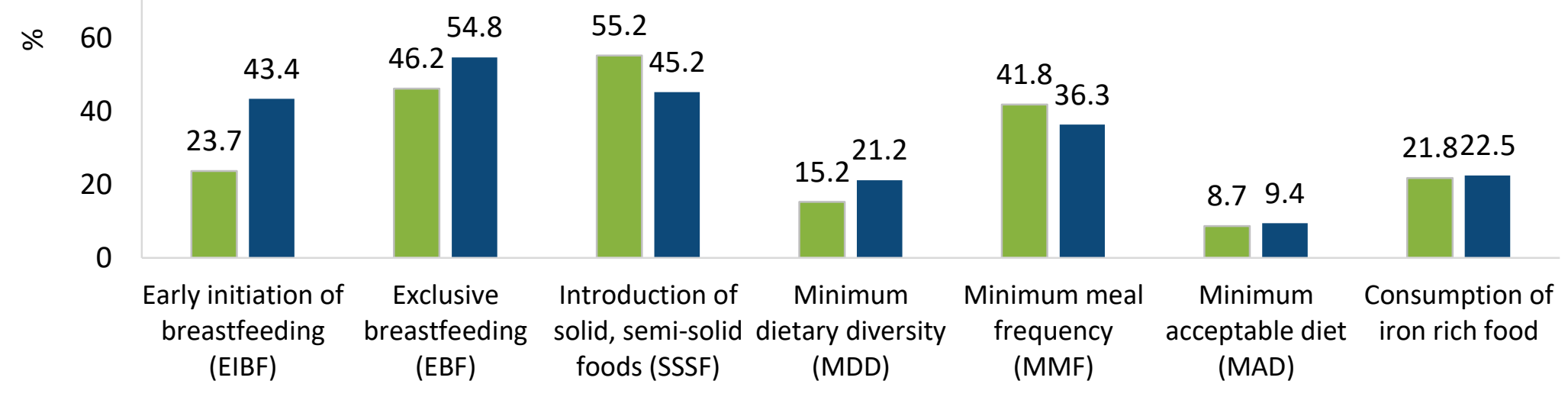

FIGURE 2 Trends in food group consumption among children (6-23 months), between 2006 and 2016

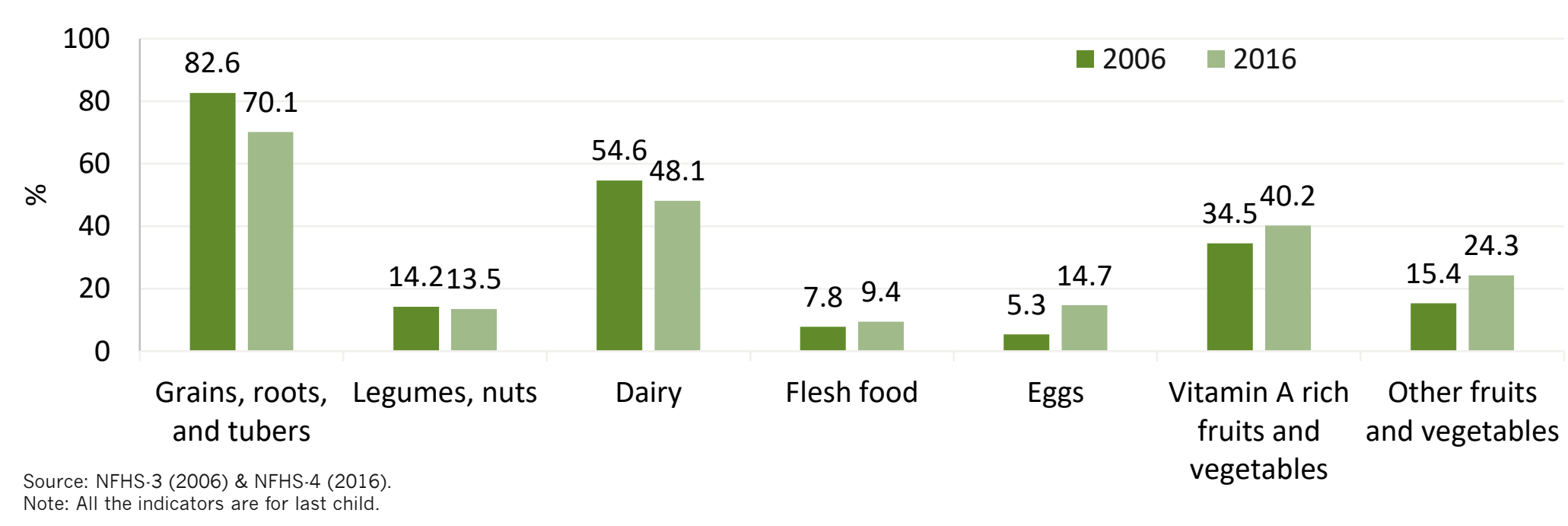

1 This document was developed prior to the Jammu and Kashmir Reorganisation Act, 2019. Hence, it does not take into account the reorganization of the state.
2 NFHS.4 followed Census 2011 district boundaries and therefore data reported in this Data Note includes 640 districts. 


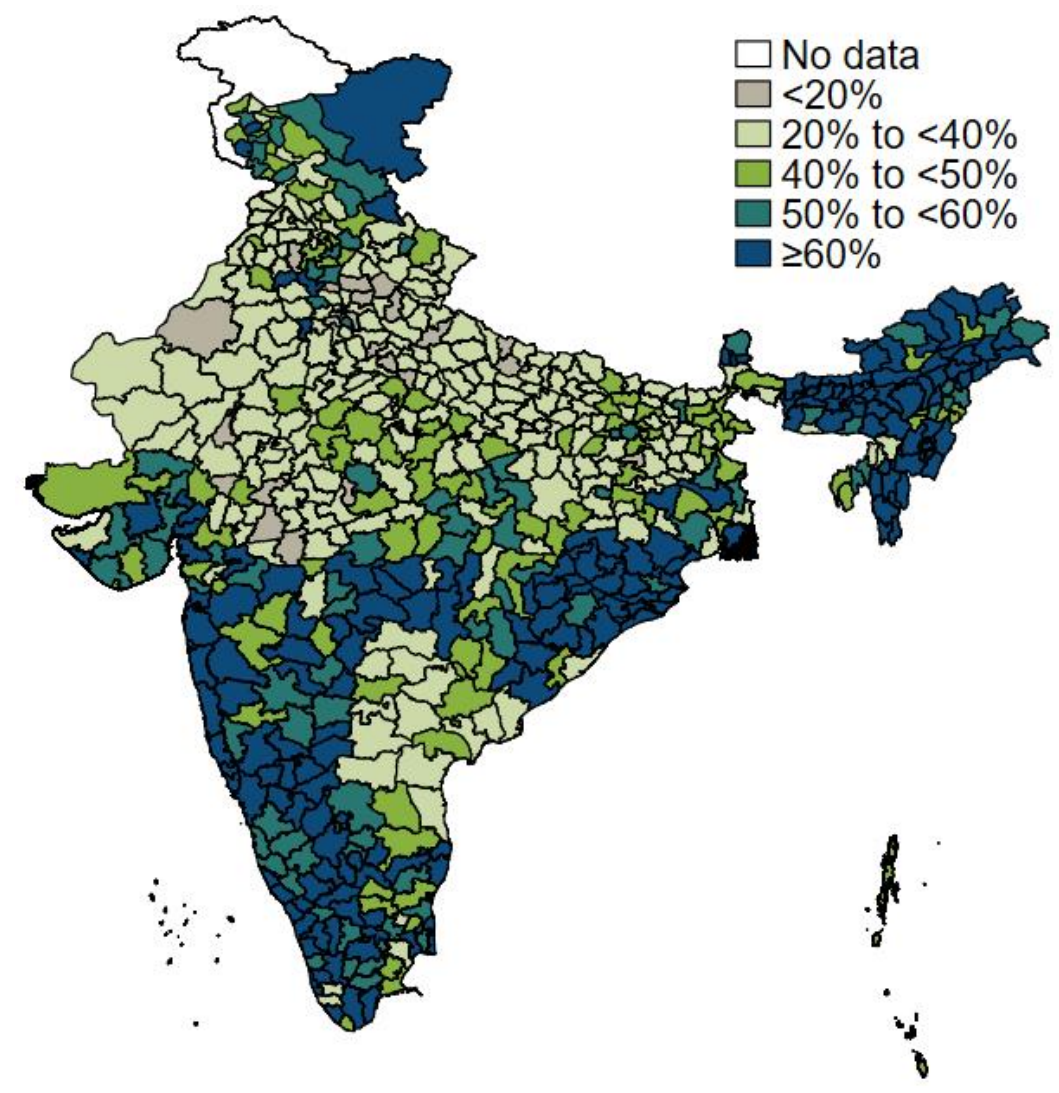

\begin{tabular}{|l|l|}
\hline \multicolumn{2}{|c}{ Top 5 districts, \% } \\
\hline Saiha (MZ) & 90.8 \\
\hline Baudh (OR) & 90.6 \\
\hline North Goa (GA) & 89.5 \\
\hline Balangir (OR) & 89.0 \\
\hline Nuapada (OR) & 88.3 \\
\hline
\end{tabular}

Source: NFHS-4.

Note: Sample size $=91,086$.

MAP 2 Percentage of children (0-5 months) who were exclusively breastfed, by district, in 2016

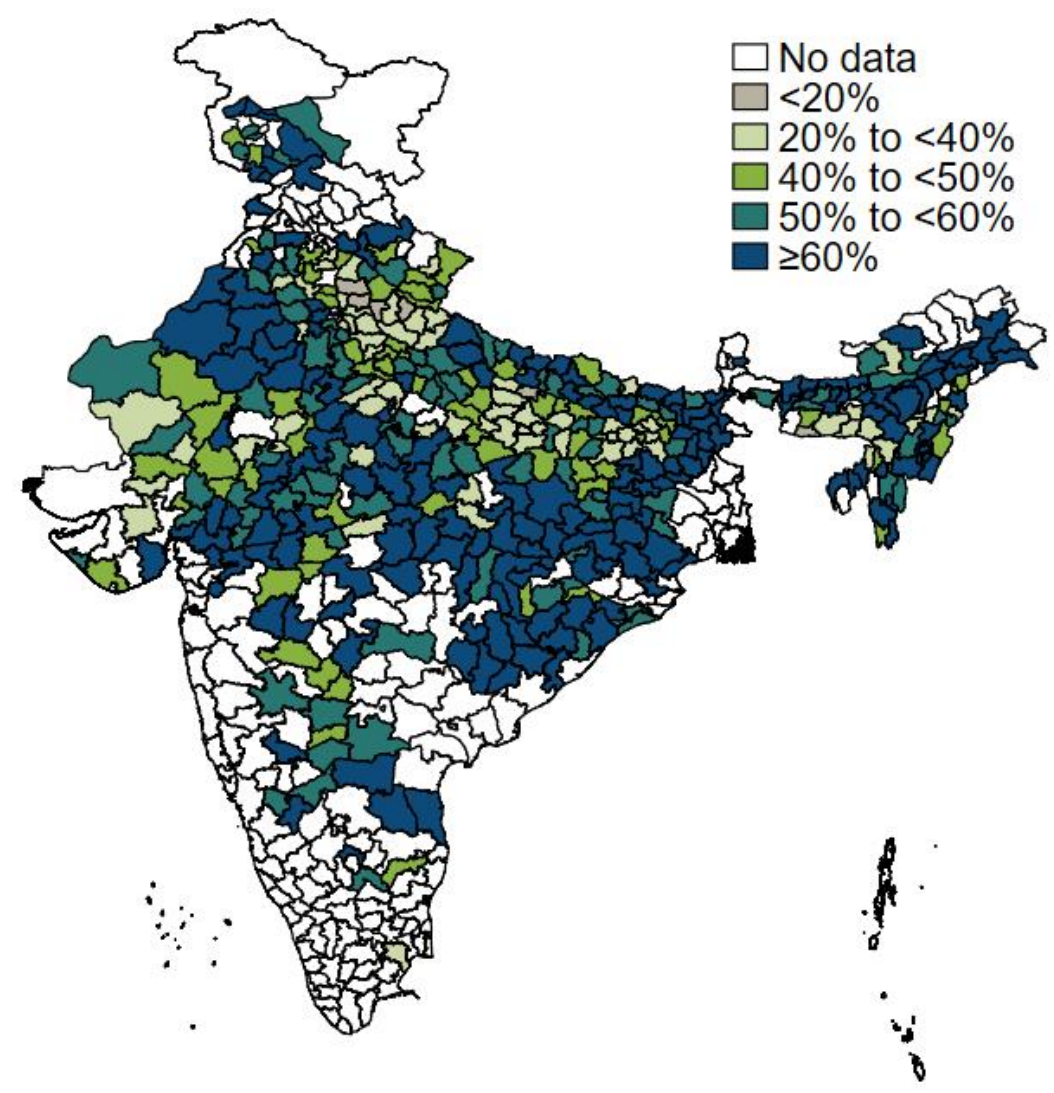

\begin{tabular}{|l|l|}
\hline \multicolumn{2}{|c|}{ Top 5 districts, \% } \\
\hline Mandsaur (MP) & 95.0 \\
\hline Churu (RJ) & 91.3 \\
\hline Jhunjhunun (RJ) & 89.1 \\
\hline Kurnool (AP) & 88.9 \\
\hline Nagpur (MH) & 88.1 \\
\hline
\end{tabular}

\begin{tabular}{|l|l|}
\hline \multicolumn{2}{|c|}{ Bottom 5 districts, \% } \\
\begin{tabular}{|l|l|} 
South Garo Hills \\
$(\mathrm{ML})$
\end{tabular} & 10.4 \\
\hline Muzaffarnagar (UP) & 13.3 \\
\hline Rampur (UP) & 15.0 \\
\hline Meerut (UP) & 15.2 \\
\hline $\begin{array}{l}\text { Ambedkar Nagar } \\
(\text { UP) }\end{array}$ & 17.4 \\
\hline
\end{tabular}



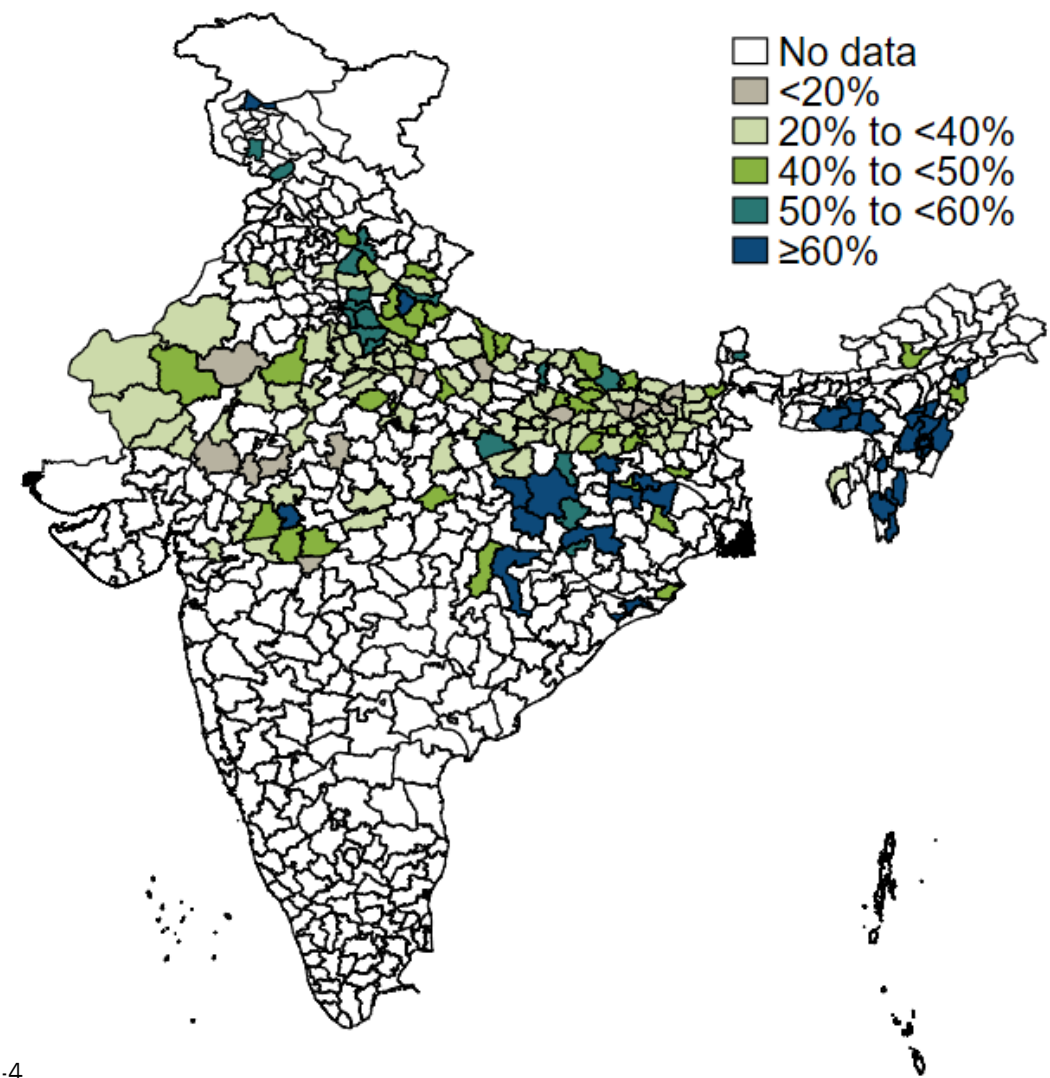

Note: Sample size $=12,788$; Data not shown for districts with fewer than 25 unweighted cases.

\begin{tabular}{|l|l|}
\hline \multicolumn{2}{|c|}{ Top 5 districts, \% } \\
\hline Tamenglong (MN) & 85.8 \\
\hline Ukhrul (MN) & 83.5 \\
\hline Senapati (MN) & 83.5 \\
\hline Bishnupur (MN) & 83.4 \\
\hline $\begin{array}{l}\text { West Khasi Hills } \\
(\mathrm{ML})\end{array}$ & 81.7 \\
\hline
\end{tabular}

Bottom 5 districts, $\%$

\begin{tabular}{|l|l|}
\hline Pratapgarh (RJ) & 7.3 \\
\hline Udaipur (RJ) & 11.0 \\
\hline Bara Banki (UP) & 15.6 \\
\hline Burhanpur (MP) & 16.1 \\
\hline Ghazipur (UP) & 16.2 \\
\hline
\end{tabular}

MAP 4 Percentage of children (6-23 months) who were fed at least a minimum number of foods groups recommended for their age, by district, in 2016

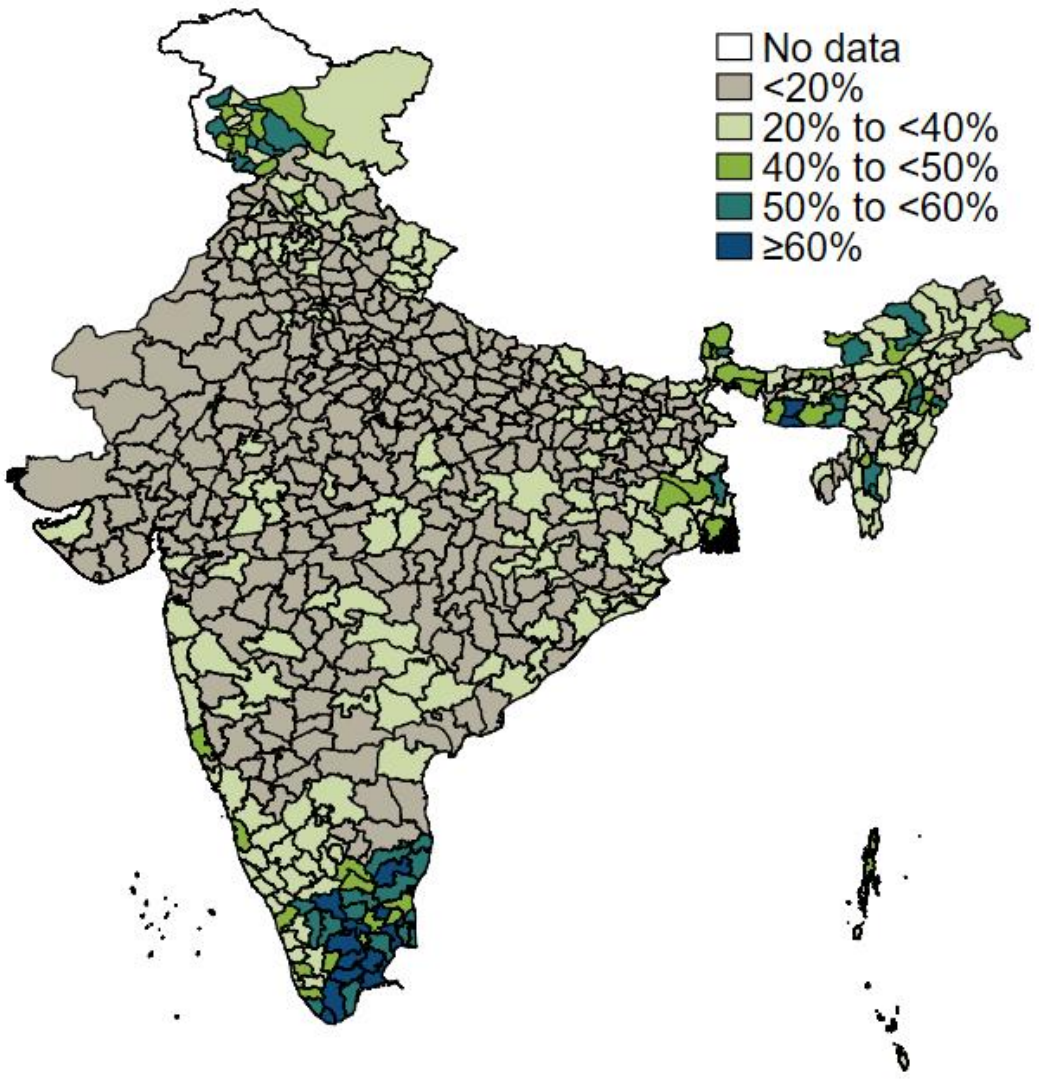

\begin{tabular}{|l|l|}
\hline \multicolumn{2}{|c|}{ Top 5 districts, \% } \\
\hline $\begin{array}{l}\text { South Garo Hills } \\
(\mathrm{ML})\end{array}$ & 78.2 \\
\hline Kanniyakumari (TN) & 70.1 \\
\hline Tirunelveli (TN) & 68.1 \\
\hline Perambalur (TN) & 67.0 \\
\hline Dindigul (TN) & 64.8 \\
\hline
\end{tabular}

Bottom 5 districts, $\%$

\begin{tabular}{|l|l|}
\hline Gurdaspur (PB) & 1.0 \\
\hline Jhalawar (RJ) & 1.1 \\
\hline $\begin{array}{l}\text { Dadra and Nagar } \\
\text { Haveli (DN) }\end{array}$ & 1.1 \\
\hline Sirsa (HR) & 1.7 \\
\hline Jalaun (UP) & 2.1 \\
\hline
\end{tabular}



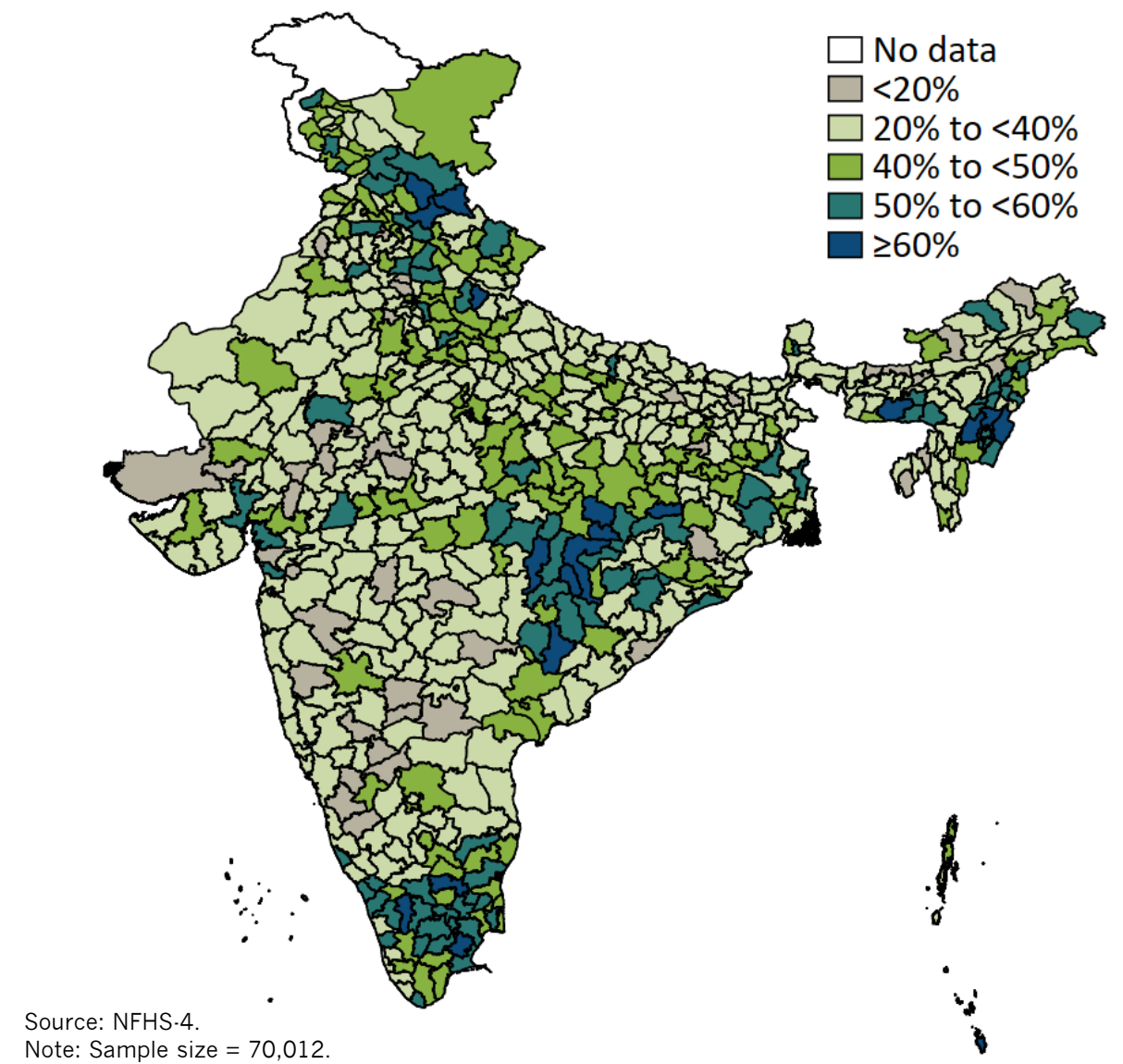

\begin{tabular}{|l|l|}
\hline \multicolumn{2}{|c|}{ Bottom 5 districts, \% } \\
\hline Upper Siang (AR) & 9.1 \\
\hline Rajgarh (MP) & 10.7 \\
\hline Darrang (AS) & 10.9 \\
\hline $\begin{array}{l}\text { Fatehgarh Sahib } \\
\text { (PB) }\end{array}$ & 11.9 \\
\hline Chittaurgarh (RJ) & 12.5 \\
\hline
\end{tabular}

MAP 6 Percentage of children (6-23 months) who consumed iron-rich food, by district, in 2016

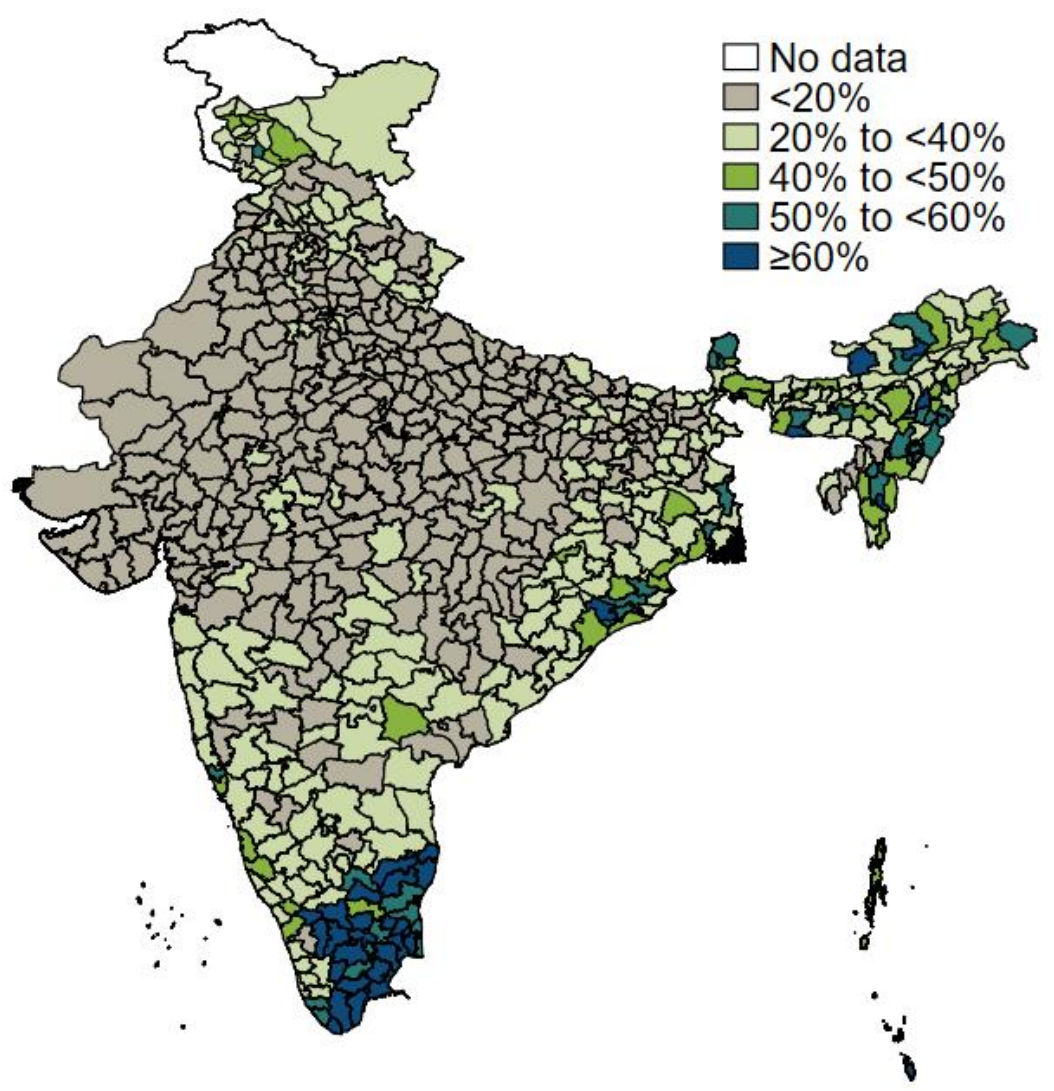

\begin{tabular}{|l|l|}
\hline \multicolumn{2}{|c|}{ Top 5 districts, \% } \\
\hline Nicobar (AN) & 84.5 \\
\hline Chennai (TN) & 81.9 \\
\hline Kanniyakumari (TN) & 81.3 \\
\hline Namakkal (TN) & 79.4 \\
\hline Karaikal (PY) & 76.7 \\
\hline
\end{tabular}

\begin{tabular}{|l|l|}
\hline \multicolumn{2}{|c|}{ Bottom 5 districts, \% } \\
\hline Budaun (UP) & 0.0 \\
\hline Panchmahal (GJ) & 1.0 \\
\hline Pilibhit (UP) & 1.3 \\
\hline Sidhi (MP) & 2.1 \\
\hline Dindori (MP) & 2.6 \\
\hline
\end{tabular}


FIGURE 3 Consumption of grains, roots, and tubers among children (6-23 months), by state, in 2016

\section{Fortified baby cereal (\%)}

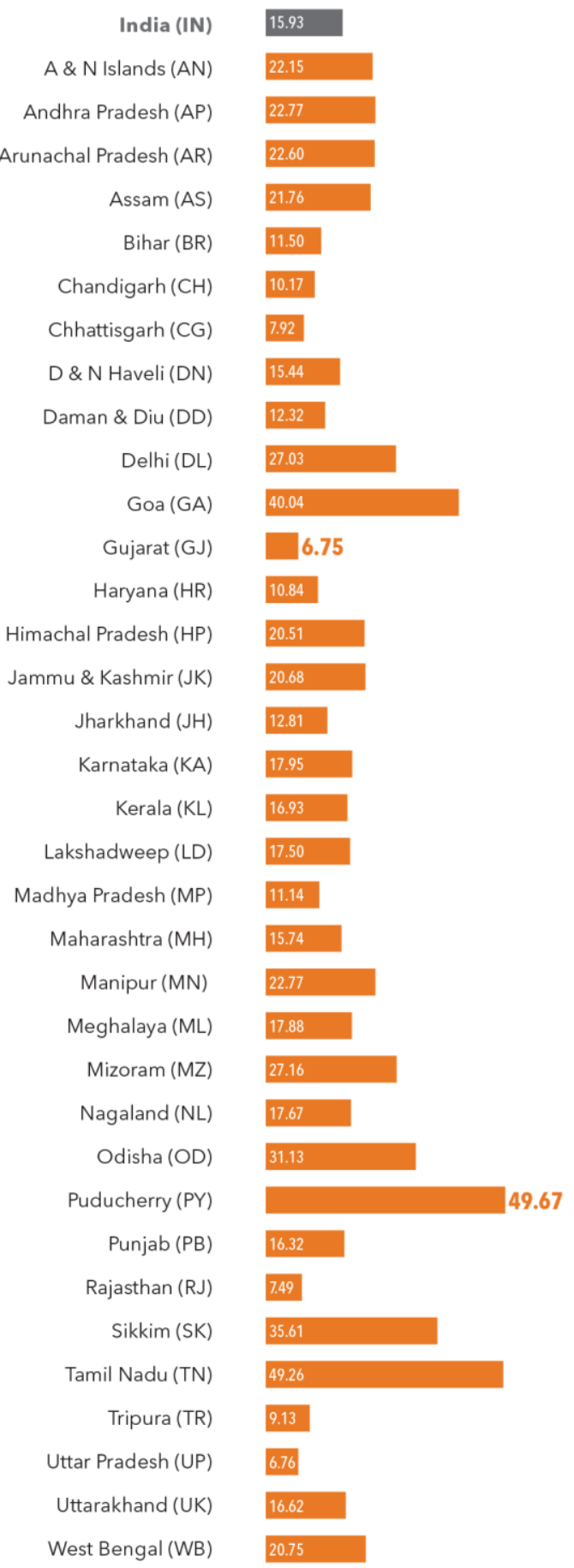

Bread/chapati/rice/other grain $(\%)$
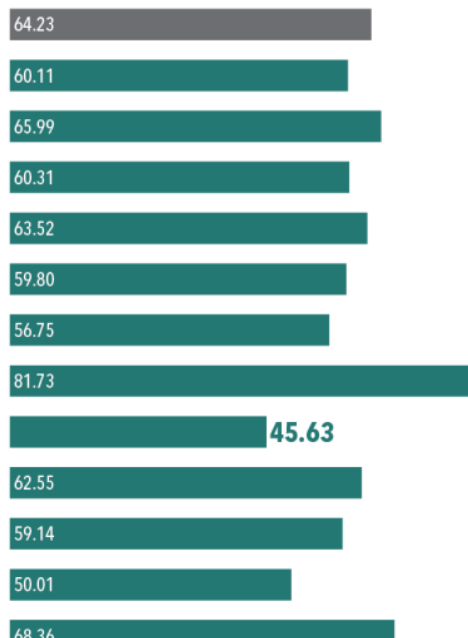

68.36

53.09
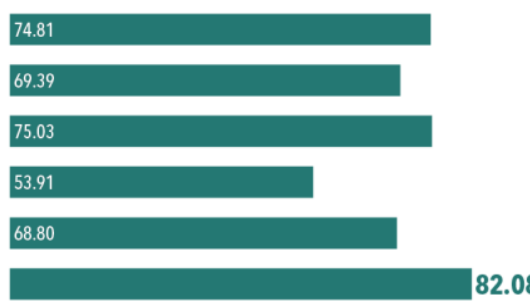

65.33
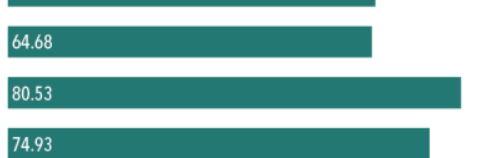

52.31
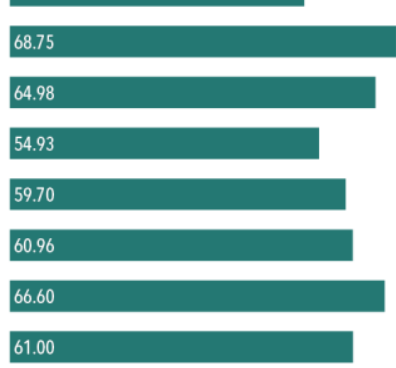

46.08

65.80

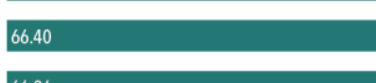

66.96
White potatoes/yams/cassava (\%)

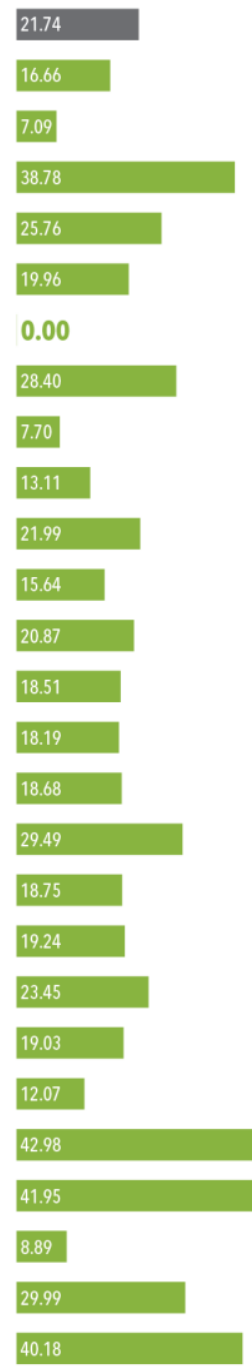

53.99

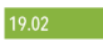

13.27
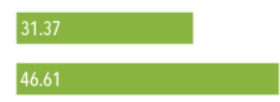

18.70

17.15

19.63

38.38
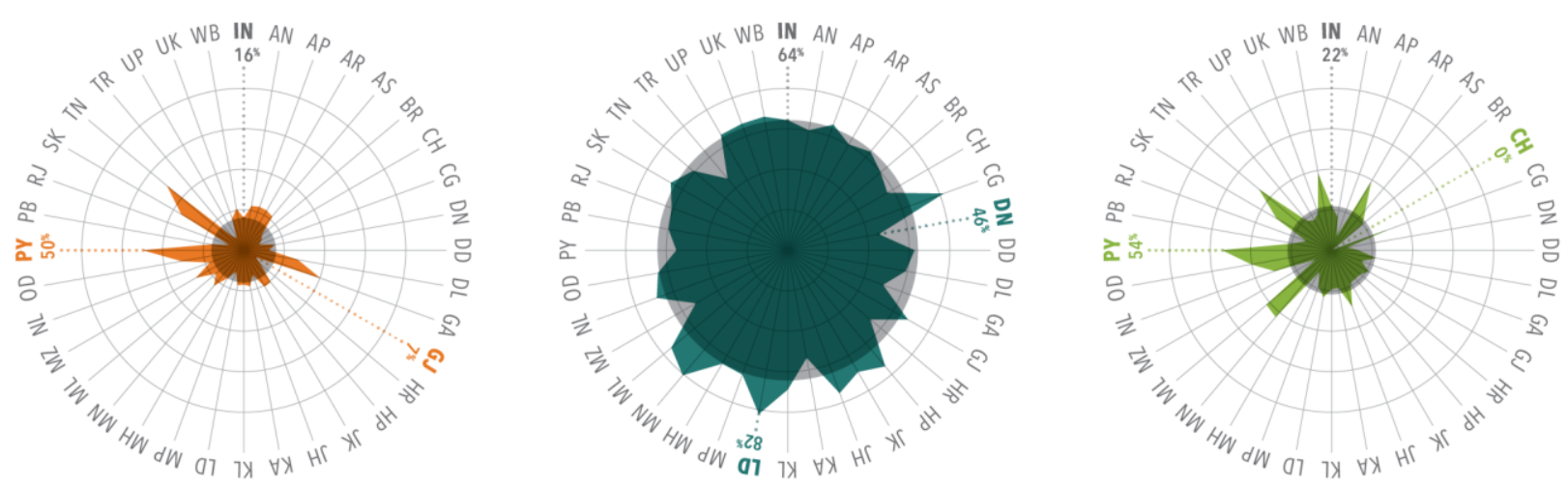
Tinned/powdered/fresh milk (\%)

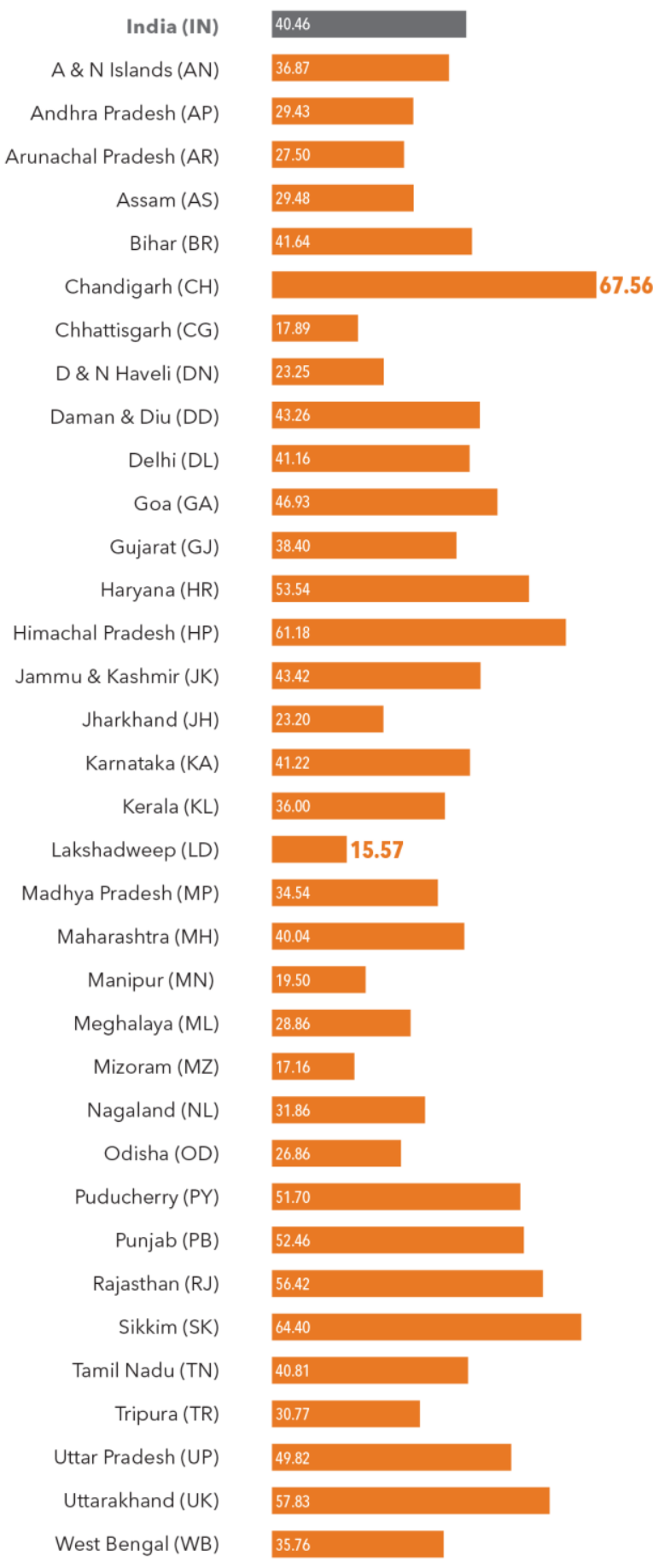

Cheese/other milk products (\%)

9.64

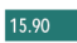

8.61

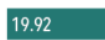

8.90

9.57

0.00

$\square .92$

2.30

14.22

16.27

11.16

$\square .71$

11.61

17.75

25.80

3.64

13.67

10.76

3.40

8.51

9.60

8.52

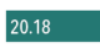

30.67

16.33

7.33

23.06

11.73

5.90

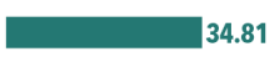

26.92

4.46

5.36

10.07

10.21

\section{Yogurt (\%)}

9.67

1.97

8.52

5.04

3.73

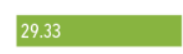

2.62

2.30

11.00

11.67

2.95

6.24

27.06

16.69

8.73

| 1.41

16.17

$\square^{4.96}$

3.33

4.94

7.13

2.43

11.05

$\square .53$

5.77

| 0.96

20.00

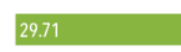

16.37

12.61

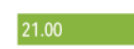

0.00

4.66

8.88
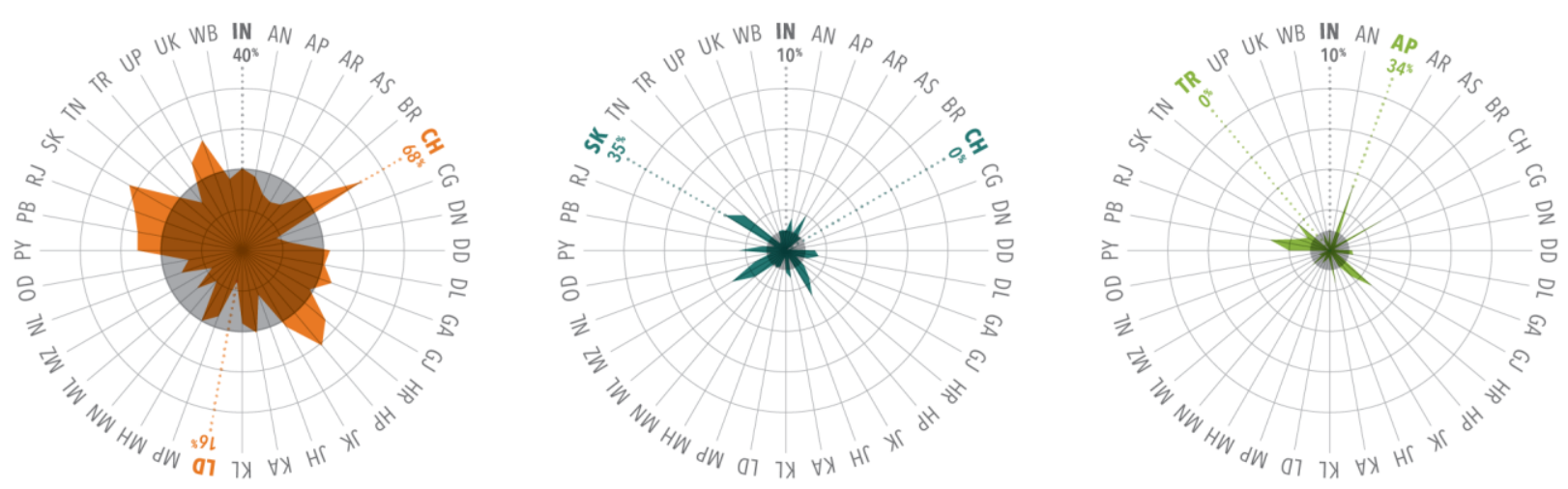
Chicken/duck/other birds (\%)

\begin{tabular}{|c|c|}
\hline India (IN) & 4.89 \\
\hline A \& N Islands (AN) & 13.56 \\
\hline Andhra Pradesh (AP) & 4.92 \\
\hline Arunachal Pradesh (AR) & 20.98 \\
\hline Assam (AS) & 8.65 \\
\hline Bihar (BR) & 5.99 \\
\hline Chandigarh $(\mathrm{CH})$ & 0.00 \\
\hline Chhattisgarh (CG) & 3.46 \\
\hline D \& N Haveli (DN) & 0.00 \\
\hline Daman \& Diu (DD) & 5.10 \\
\hline Delhi (DL) & 3.21 \\
\hline Goa (GA) & 5.02 \\
\hline Gujarat (GJ) & | 1.43 \\
\hline Haryana (HR) & | 1.36 \\
\hline Himachal Pradesh (HP) & | 1.24 \\
\hline Jammu \& Kashmir (JK) & 20.81 \\
\hline Jharkhand (JH) & 5.56 \\
\hline Karnataka (KA) & 6.46 \\
\hline Kerala (KL) & 8.09 \\
\hline Lakshadweep (LD) & | 1.07 \\
\hline Madhya Pradesh (MP) & 2.44 \\
\hline Maharashtra (MH) & 4.01 \\
\hline Manipur (MN) & 21.30 \\
\hline Meghalaya (ML) & 19.58 \\
\hline Mizoram (MZ) & 14.81 \\
\hline Nagaland (NL) & \\
\hline Odisha (OD) & 4.77 \\
\hline Puducherry (PY) & 17.64 \\
\hline Punjab (PB) & $\mid 0.51$ \\
\hline Rajasthan (RJ) & $\mid 0.65$ \\
\hline Sikkim (SK) & 26.15 \\
\hline Tamil Nadu (TN) & 14.51 \\
\hline Tripura (TR) & 5.31 \\
\hline Uttar Pradesh (UP) & | 1.30 \\
\hline Uttarakhand (UK) & | 1.64 \\
\hline West Bengal (WB) & 8.75 \\
\hline
\end{tabular}

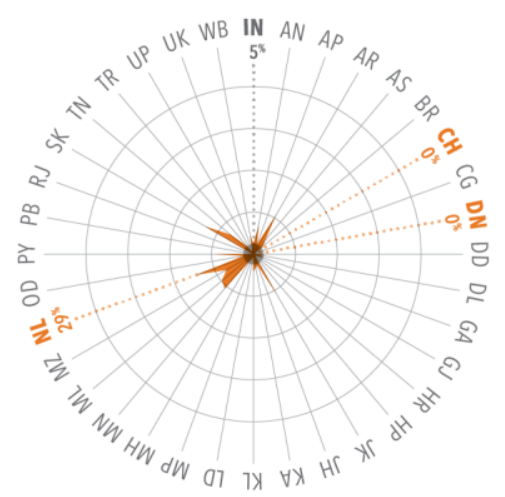

Fish/shellfish (\%)

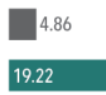

2.66

16.25

6.82

1.88

0.00

1.72

0.00

6.26

1.95

15.55

| 1.06

|0.78

0.08

6.50

2.63

5.34

19.84

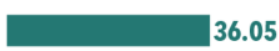

| 1.78

3.48
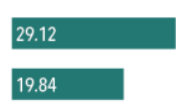

24.54

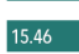

4.52

30.41

| 0.57

$\mid 0.25$

13.10

26.85

4.66

| 0.75

| 0.85

9.89
Liver/kidney/heart (\%)

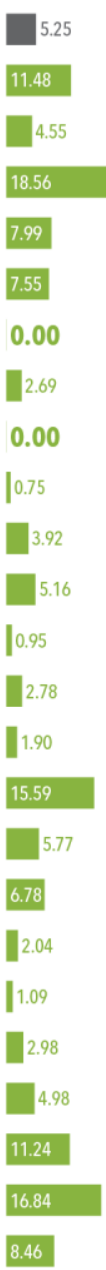

8.46

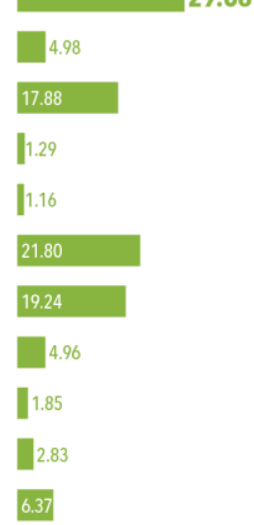

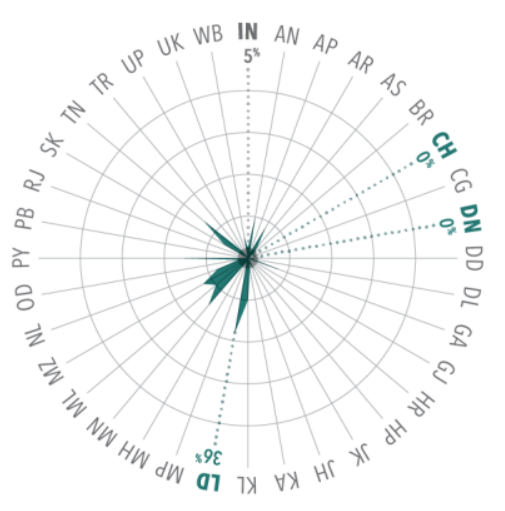

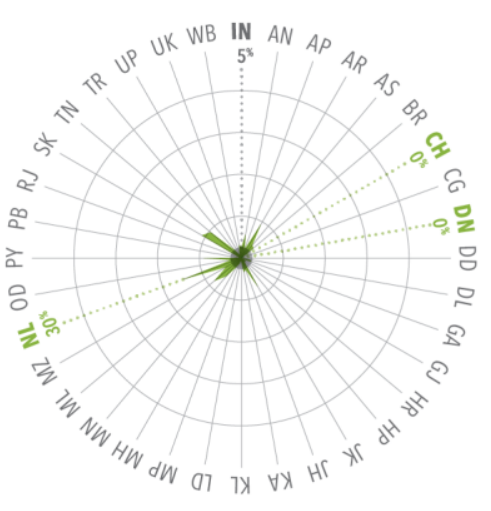


FIGURE 6 Consumption of vitamin-A rich fruits and vegetables among children (6-23 months), by state, in 2016

Pumpkin/carrots/squash (\%)

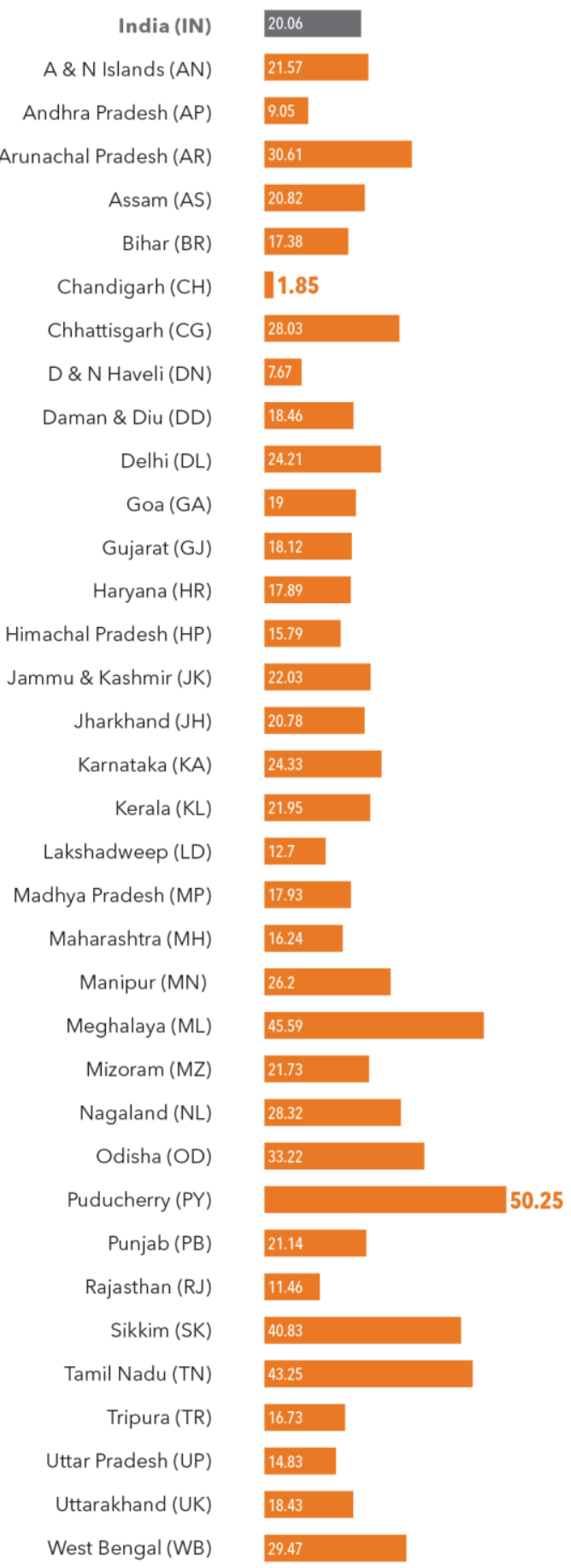

Any dark green leafy vegetables (\%)
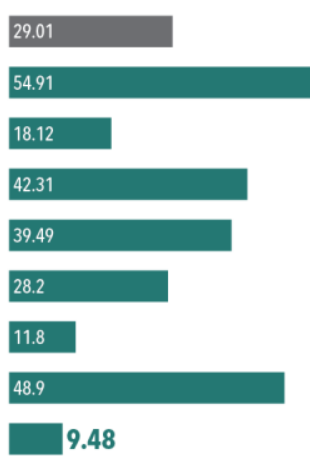

25.23

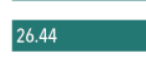

20.25

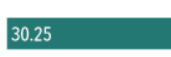

23.4
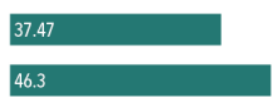

32.21

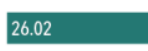

17.52

14.25

27.18
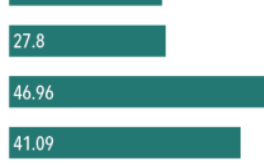

50.49

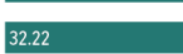

52.17
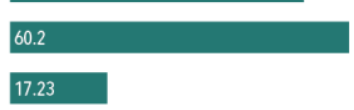

15.64

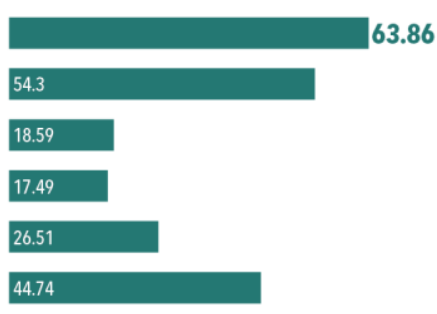

Ripe mangoes/papayas/

other vitamin A-rich fruits (\%)

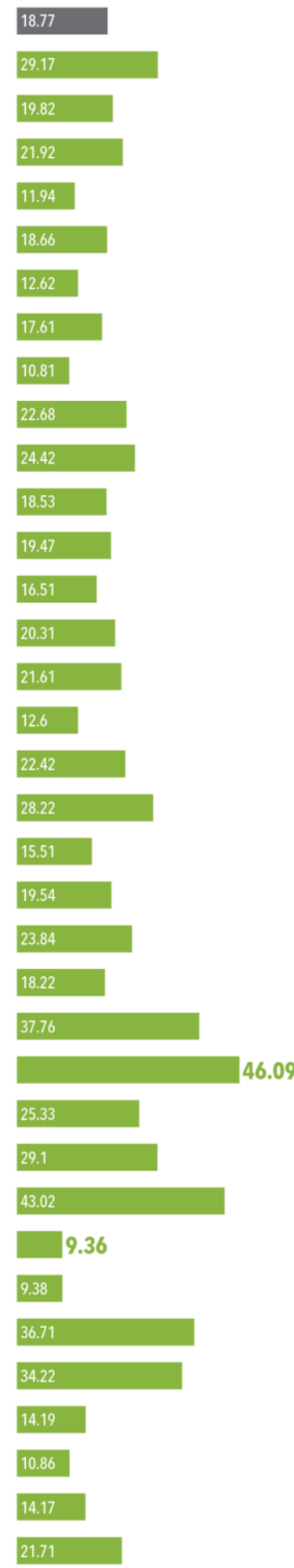

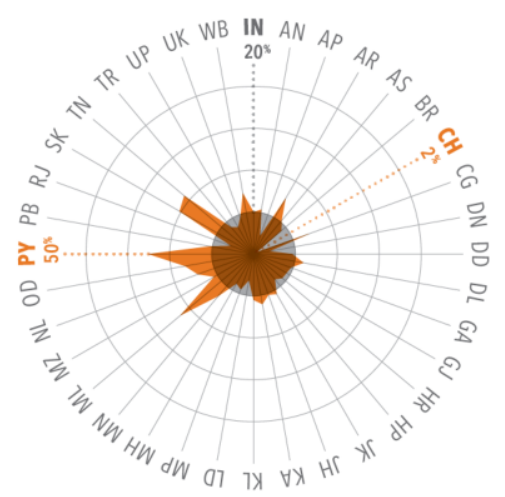
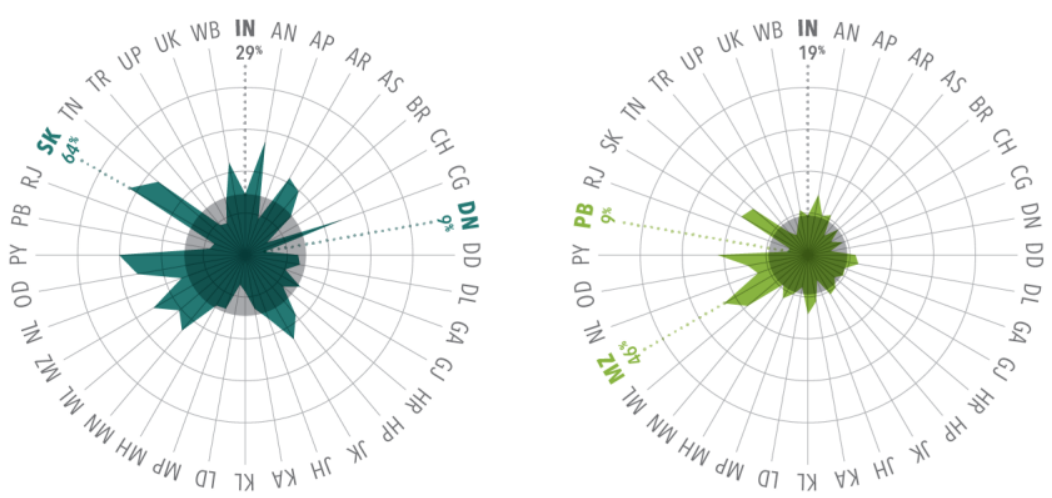
FIGURE 7 Consumption of legumes and nuts, egg, and other fruits and vegetables among children (6-23 months), by state, in 2016

\section{Legumes/nuts (\%)}
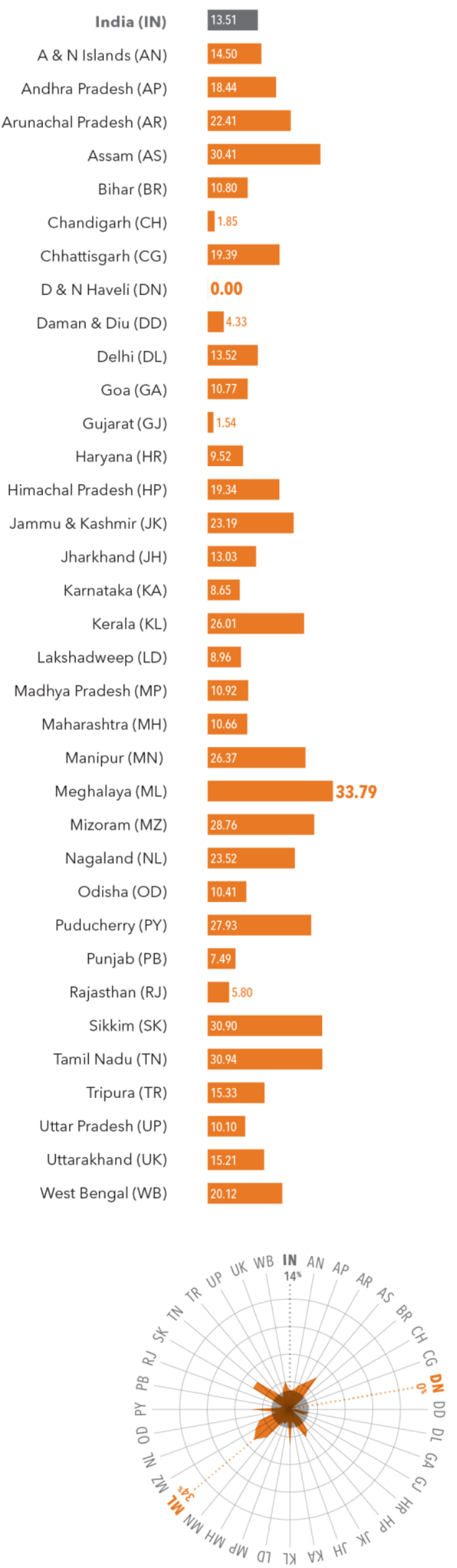

$\operatorname{Egg}(\%)$

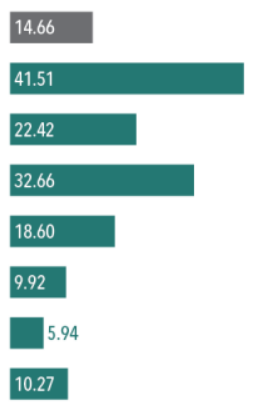

| 1.11

18.10

9.96

14.71

3.51

6.45

3.67

37.35

8.87

17.57

25.41

18.93

6.03

13.01
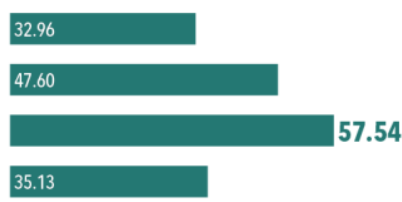

12.63

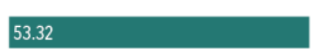

5.79

1.91
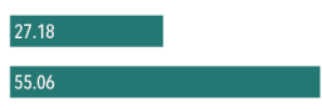

16.45

3.69

7.01

36.33

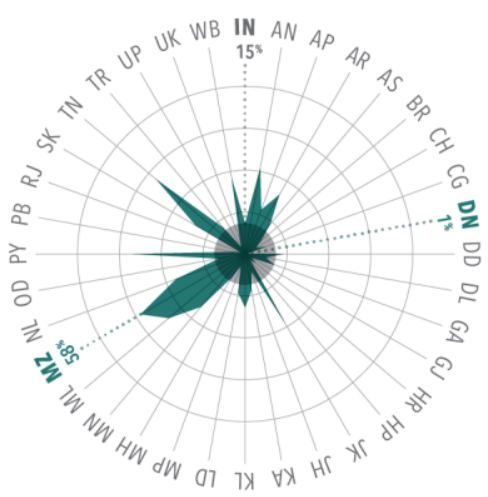

Other fruits/vegetables (\%)

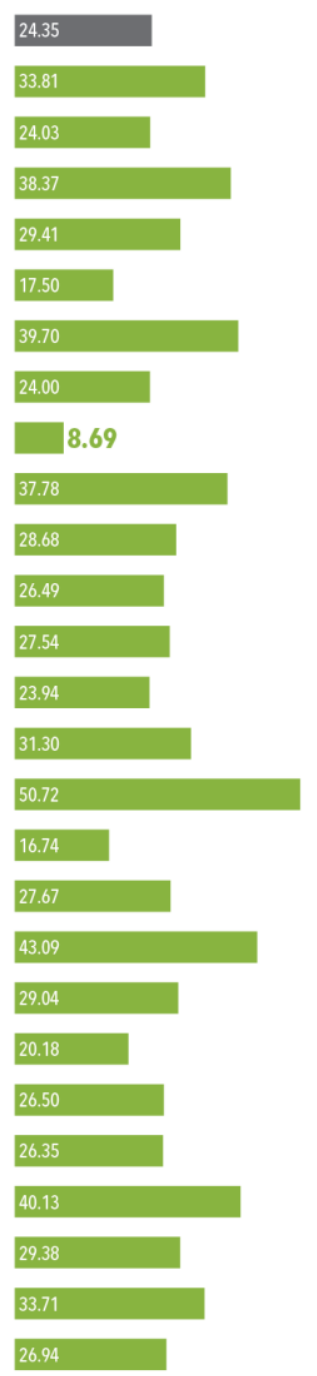

59.53

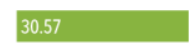

13.74

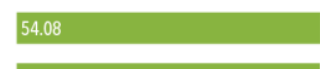

53.88

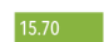

14.41

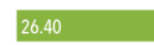

31.32 


\begin{tabular}{|c|c|c|c|c|c|c|}
\hline \multirow[t]{3}{*}{ IYCF practices } & \multicolumn{5}{|c|}{ Prevalence category (\%) } & \multirow{3}{*}{$\begin{array}{l}\text { Number of } \\
\text { districts } \\
\text { with no } \\
\text { data }^{3}\end{array}$} \\
\hline & $0-19.9$ & 20-39.9 & $40-49.9$ & $50-59.9$ & $\geq 60$ & \\
\hline & \multicolumn{5}{|c|}{ Number of districts in prevalence categories } & \\
\hline Early initiation of breastfeeding & 24 & 233 & 113 & 88 & 182 & 0 \\
\hline Exclusive breastfeeding & 6 & 66 & 69 & 96 & 186 & 217 \\
\hline $\begin{array}{l}\text { Timely introduction of solid and semi } \\
\text { solid food }\end{array}$ & 13 & 79 & 37 & 18 & 32 & 461 \\
\hline Minimum dietary diversity & 344 & 201 & 42 & 38 & 15 & 0 \\
\hline Minimum meal frequency & 42 & 341 & 151 & 86 & 20 & 0 \\
\hline Iron-rich food & 310 & 213 & 44 & 37 & 36 & 0 \\
\hline
\end{tabular}

${ }^{3}$ Districts with fewer than 25 unweighted cases were not included.

\section{Key findings, messages and recommendations}

Data on the trends and patterns in infant and young child feeding practices and food consumption patterns among children highlight that IYCF practices are poor and that food consumption patterns vary widely by districts and states. Major data gaps, mainly due to small sample sizes, mean that in several districts, it is not possible to know how babies are fed.

\section{Early Initiation of Breastfeeding (EIBF) \&}

Exclusive Breastfeeding (EBF) : Between 2006 and 2016, there was a significant improvement in breastfeeding practices (Figure 1). EIBF nearly doubled (from 23 percent to 42 percent), and EBF increased from 46 percent to 55 percent during this period. However, it is concerning to note that in 2016, out of 640 districts, prevalence of EIBF was 60 percent or higher in less than a third of the districts (Map 1). Data for exclusively breastfed children was available only in 423 out of 640 districts. Hence, there is a need to:

- Close the data gaps for exclusive breastfeeding.

- Promote EIBF and EBF through concerted behavior change communication.

Timely introduction of solid/semi-solid food : Between 2006 and 2016, there was nearly a 10-percentage-point decline in the timely introduction of solid or semi-solid foods (from 55 percent to 45 percent). In 2016, data for children (6.8 months) who received solid/semi solid foods in a timely manner was available in less than a third of the districts (only in 179 out of 640 districts). Of these 179 districts, timely introduction of solid/semi-solid foods was $\geq 60$ percent in only 32 districts (Map 3). This indicates that: special emphasis through intense behavior change communication and accompanying interventions such as the use of the ICDS food supplements.

- A narrow age range for the timely introduction indicator leads to huge data gaps. Innovative approaches to close this are needed.

Minimum Dietary Diversity (MDD) : Between 2006 and 2016, MDD increased slightly (15 percent to 21 percent). But in 2016, in more than half the districts in the country (344 out of 640 districts), the level of MDD was $\leq 20$ percent, which is a matter of concern (Map 4). Of the 15 districts where MDD was more than 60 percent, most were in Tamil Nadu.

Trends in food group consumption patterns among children (6.23 months), between 2006 and 2016, show a marginal improvement in the consumption of flesh foods, eggs, vitamin-A rich fruits and vegetables and other fruits and vegetable (Figure 2). However, there was a decline in the consumption of some food groups including grains, roots and tubers, legumes and nuts, and dairy products.

In 2016, only 13 percent of children (6-23 months) in India consumed foods from legumes $\&$ nuts group. Less than a quarter of children ( 24 percent) consumed other fruits and vegetables. 
Only 15 percent of children consumed eggs and just about 9 percent consumed flesh foods, in 2016. This calls for:

- A nation-wide campaign to increase awareness on the importance of dietary diversity to make better diets aspirational.

- Highlighting the nutrient benefits of legumes \& nuts, flesh foods and eggs and promoting their consumption, especially among growing children.

- Promotion of dietary diversity through agricultural, livelihood, and social safety-net interventions.

- Investing in addressing major food systems issues, including food prices and food availability to ensure diet diversity.

\section{Minimum Meal Frequency (MMF) and Minimum} Acceptable Diet (MAD): It is a matter of concern that MMF decreased from 42 percent in 2006 to 36 percent in 2016. Minimum acceptable diet ( $~ 9$ percent) was extremely low and did not change much over this period (Figure 1). The Comprehensive National Nutrition Survey (CNNS) results of 2016-18 also show that only 6.4 percent of children under the age of two years get minimum acceptable diet in India. To meet the nutrition targets set by the National Nutrition Mission (or POSHAN Abhiyaan), it is essential to:

- Examine the role of Take-Home Rations, under the Integrated Child Development Services' Supplementary Nutrition Program, in relation to the overall feeding patterns.
- Improve policy guidance, policy coordination and monitoring of existing programs on food supplementation and fortification.

Consumption of iron-rich foods: Between 2006 and 2016, consumption of iron-rich foods remained stagnant at around 20 percent. In 2016 , out of 640 districts, consumption of iron-rich foods was $\geq 60$ percent in only 36 districts (Map 6). Districts with the highest levels of iron-rich food consumption ( $>70$ percent) in 2016, were in Tamil Nadu, Meghalaya, Puducherry and Andaman \& Nicobar Islands.

A primary reason to encourage the consumption of iron-rich food is that iron deficiency is an important cause of anemia, which is widely prevalent among 1.4 year-old children according to CNNS 2016-18. To encourage the consumption of iron-rich foods, it is important to:

- Generate awareness about the health benefits of an iron-rich diet, its sources, and the significance of adding a source of vitamin C to enhance iron absorption.

- Improve availability of data on outcomes and determinants of iron deficiency, and their relation to food consumption patterns.

- Improve policy guidance, policy coordination and monitoring of existing programs on iron supplementation and iron fortification.

\section{Definitions}

Early initiation of breastfeeding: Proportion of children born in the last 24 months who were put to the breast within one hour of birth.

Exclusive breastfeeding: Proportion of infants $0-5$ months of age who are fed exclusively with breast milk.

Introduction of solid, semi-solid foods: Proportion of infants 6-8 months of age who receive solid, semi-solid or soft foods.

Minimum dietary diversity: Proportion of children 6-23 months of age who receive foods from 4 or more food groups.

Minimum meal frequency: Proportion of breastfed and non-breastfed children 6-23 months of age who receive solid, semi-solid, or soft foods (but also including milk feeds for non-breastfed children) the minimum number of times or more.

Minimum acceptable diet: Proportion of children 6-23 months of age who receive a minimum acceptable diet (apart from breast milk).

Consumption of iron rich food: Proportion of children 6-23 months of age who receive an iron-rich food or iron-fortified food that is specially designed for infants and young children, or that is fortified in the home.

Source: https://www.who.int/nutrition/publications/infantfeeding/9789241599290/en/

Note: 1 . The number of districts in the maps for exclusive breastfeeding and for introduction of solid/semi-solid foods are 423 and 179 , respectively, because the districts with fewer than 25 unweighted cases were not included. 2. Estimates used in this Data Note are for both breastfed children and non-breastfed children.

Codes for States and Union Territories

AN - Andaman \& Nicobar Islands

AP. Andhra Pradesh

AR - Arunachal Pradesh

AS - Assam

BR - Bihar

$\mathrm{CH} \cdot$ Chandigarh

CT - Chhattisgarh

DN - Dadra \& Nagar Haveli

DD - Daman \& Diu

DL - Delhi
GA - Goa
GJ - Gujarat
HR - Haryana
HP - Himachal Pradesh
JK - Jammu \& Kashmir
JH - Jharkhand
KA - Karnataka
KL - Kerala

$\mathrm{KL} \cdot$ Kerala

LD - Lakshadweep
MP - Madhya Pradesh
MH - Maharashtra
MN - Manipur
ML - Meghalaya
MZ - Mizoram
NL - Nagaland
OR - Odisha
PY - Puducherry

LD - Lakshadweep

$\mathrm{MH}$ - Maharashtra

$\mathrm{MZ} \cdot$ Mizoram

OR - Odisha

PY - Puducherry
PB - Punjab

RJ - Rajasthan

SK - Sikkim

TN - Tamil Nadu

TG - Telangana

TR - Tripura

UT - Uttarakhand

UP - Uttar Pradesh

WB - West Bengal 


\section{Led by IFPRI}

\section{AUTHORS}

Phuong Hong Nguyen, Research Fellow, IFPRI

Rasmi Avula, Research Fellow, IFPRI

Anjali Pant, Research Analyst, IFPRI

Esha Sarswat, Communications Specialist, IFPRI

Pratima Mathews, Senior Communications Specialist, IFPRI

Purnima Menon, Senior Research Fellow, IFPRI

\section{SUGGESTED CITATION}

Nguyen, P. H., R. Avula, A. Pant, E. Sarswat, P. Mathews and P. Menon. 2019. Feeding India's Babies: Trends and Patterns in Infant and Young Child Feeding Practices Across India's States and Districts. POSHAN Data Note 36. New Delhi, India: International Food Policy Research Institute.

\section{ACKNOWLEDGEMENTS}

Lan Mai Tran, Independent Researcher Jason Chow, Graphic Designer, IFPRI

\section{ABOUT POSHAN}

Partnerships and Opportunities to Strengthen and Harmonize Actions for Nutrition in India (POSHAN) is a multi-year initiative that aims to support the use of data and evidence in decision-making for nutrition in India. It is supported by the Bill \& Melinda Gates Foundation and led by IFPRI in India.

http://poshan.ifpri.info/

\section{ABOUT DATA NOTES}

POSHAN Data Notes focus on data visualization to highlight geographic and/or thematic issues related to nutrition in India. They draw on multiple sources of publically available data.

\section{CONTACT US}

Email: IFPRI-POSHAN@cgiar.org

\section{IFPRI-NEW DELHI}

\section{INTERNATIONAL FOOD POLICY} RESEARCH INSTITUTE

NASC Complex, CG Block,

Dev Prakash Shastri Road,

Pusa, New Delhi 110012, India

$\mathrm{T}+91.11 .66166565$

$F+91.11 .66781699$

\author{
IFPRI-HEADQUARTERS \\ INTERNATIONAL FOOD POLICY \\ RESEARCH INSTITUTE \\ 1201 Eye Street, NW, \\ Washington, DC 20005 USA \\ T. +1.202 .862 .5600$ \\ F. +1.202 .467 .4439$ \\ Skype: IFPRIhomeoffice \\ ifpri@cgiar.org \\ www.ifpri.org
}

Disclaimer: The maps used in this Data Note are based on the territorial jurisdictions of the Government of India's 2011 census. The boundaries shown do not imply any official endorsement or acceptance by IFPRI.
This publication has been prepared by POSHAN. It has not been peer reviewed. Any opinions stated herein are those of the author(s) and do not necessarily reflect the policies of the International Food Policy Research Institute.

Copyright (?) 2019 International Food Policy Research Institute. All rights reserved. For permission to republish, contact ifpri-copyright@cgiar.org. 